\title{
Factors That Affect the Desire of the Second-Child Birth
}

\author{
Jinguo Wang \\ Department of Urology \\ The First Hospital of Jilin University \\ Changchun, China \\ wangjinguolily@163.com
}

\author{
Corresponding author: Na Wang* \\ Department of Anesthesiology \\ The First Hospital of Jilin University \\ Changchun, China \\ wangna080613@163.com
}

\begin{abstract}
According to Chinese unique and profound cultural background, experts in China combine with international children cost-utility theory and divide the cost of raising a child in China into economic cost, opportunity cost and psychological cost. In the mean time, they divide the utility of children into economic utility, expected insurance utility and happy utility. On the base of the related research, the most important influencing factor of the desire of the second-child birth is child raising cost which will have a significant impact on reproductive decisions.
\end{abstract}

Keywords-fertility intentions; two-child policy; child raising cost; cost-utility theory

\section{INTRODUCTION}

Along with our country individual second child birth policy of gradually relaxing and perfect, separate two-child childbearing willing choice gradually become a hot research topic, this paper discuss the utility cost of children and their children to individual family's second child fertility intentions through literature study, and based on the child's cost utility theory for the main cost factor affecting the second child of childbearing willing choice and the main effect factors were studied [1]. This article finally found economic factors as the main factors, at the same time some non-economic factors have obvious effect.

\section{SECOND CHILD BACKGROUND}

Along with our country the implementation of the one-child policy, China's total fertility rate has been below replacement level, into the low fertility countries club. Demographic dividend gradually disappear, at the same time, China's population aging and the one-child problems stand out gradually, in order to alleviate the problem of severe low fertility, through separate two new policy in our country, the both sides of husband and wife have one party is only children, can have two children alone, whether the policy can smooth implementation is still in the exploratory stage, thus understand the city urban and rural residents to separate two child policy after the second child birth choices and main factor [2].

Critical fertility intentions as the embodiment of fertility culture, including the number of desired childbearing number of children, gender, birth child sex and time, intend to have children [3]. These three factors directly decides the people to the reproductive number, gender preference and motives of choice, although fertility intentions and there may be some deviation between fertility behavior, but through fertility intentions survey, understand the urban and rural residents to separate two-child family needs, and the main factors influencing the fertility behavior is helpful to scientific judgment birth rate along with our country residents' income and the quality of life gradually improve, people tend to be more rational for the choice of the second child birth [4].

This article is based on utility theory, urban and rural residents in China's second child birth alone will influence factors were analyzed, and discussed the influence of related factors for single family childbearing willing, in order to China's future population policy adjustment and population development plan to provide the reference [5].

\section{FACTORS AFFECTING THE DESIRE}

In the last century, western developed countries population fertility falling caused many scholars research on the theory of fertility. Birth policy is not restricted in the marriage the only determinant of two births crowd, it is also influenced by personal background, economic strength, social and cultural factors. This study results show that the double one-child family, single family and the only family's second child birth will not exist obvious differences, studies have also pointed out that the double only couples with other young couples have almost exactly the same age of childbearing willing [6]. Older objects the will of the two births is lower, especially in more than 30 years of age is more obvious, this may and they have passed fit of the fertility, experts research, points out that with the increase of age, the cost of children will be more and more high [7]. On the one hand because of biology, older women's reproductive risk increases, increases the difficulty of raising children. On the other hand is the cause of the economics, the average personal income will increase with age, time cost and raising-child time spending more inelastic, hence fertility intentions also showed a trend of decrease with age.

Annual household income level higher respondents second child fertility intention is higher, because their economic power is stronger, more easily costs of raising two children. It can get old man helper because the old man can share some of the children born to raise and take care of pressure, two high fertility intentions. Physical health has poor second child birth will lower, because of poor health will make women's 
reproductive risk is bigger, and the children also increase the risk of suffering from congenital diseases [8].

In addition, the study also shows that, in addition to personal and willingness of spouse, economic ability to become a main consideration reason to decide whether two births, suggests that the parental cost increase has certain effects on the willingness of people to breed. Household income and housing are one-child family considers to choose the main economic factor.

\section{THE THEORY RESEARCH}

Society is made up of people, so no one is the existence of the society as a whole is gone. Cost utility theory and related research, combining with children will have a child of the utility is mainly divided into economic utility, insurance and utility to utility and pleasure. Among them, the economic utility including child future bring family wealth, future parents endowment insurance mainly includes the utility, avoid future become empty-nesters security safeguard, and the child into reincarnation utility including the family prosperous, the enjoyment of utility including children make parents satisfied mentally [9]. Financial support in the economic utility of the main body, old-age security and education in the insurance utility optimization is the main body, child-bearing utility and spirit to meet the utility is still widely recognized.

Separate the implementation of the two-child policy will bring down the level of ageing, calculation results show that the implementation of separate two-child policy compared with the current policy unchanged, relative to the previous birth policy either predicted results, showed that separate the implementation of the two-child policy to alleviate the serious situation of aging population in China is very heavy, especially for long-term aging of population in our country has a significant reduction in action [10].

In this sense, the implementation of separate two-child policy not only can more time to prepare for dealing with aging, but also directly reduce the level of an aging population.

Thus, in the China of old before rich simply by government pension model to solve the problem of an increasingly large scale of the elderly pension has a great challenge, and adjustment of fertility policies help to boost the birth rate, can make the new birth population gradually grow into the working-age population, increase social security payment group, and reduce the elderly dependency ratio, which to a certain extent, ease the labor age population decline and increase the pressure of old-age security [11]. Separate the twochild policy implementation, which is beneficial to the adjustment of the family structure in China, to improve the ability of the traditional family endowment. In this way, by two children share the responsibility of family pension, no doubt enhance the function of family pension; also relatively ease the pressure on the government and social old-age security.

\section{THE DesiRe OF THE SECOND CHILD IN CHINA}

Fertility intention refers to the individual in terms of children's wishes and requirements, mainly from the number of children, children's gender, birth time these three aspects to show, that is to say any fertility is a certain amount, time, and gender of fertility. It is referred to this article mainly from the town of childbearing willing individual family planning purpose, reproductive age, birth child sex between these dimensions.

Fertility value orientation in different level of the social productivity can be divided into traditional social fertility intentions and fertility intentions two categories of modern society. Therefore, compared with the traditional concept of fertility, now people reduces the reincarnation of the utility value for children, the idea of a traditional preference for sons also change, at the same time, with the rising cost of living, as well as the increasing of the empty nest elderly, for children to compare an obvious economic and pension rely on, two children can share the family economic pressure, share the parents endowment pressure, also can reduce the risk of parents alone, take care of the responsibility of parents.

\section{A. Fertility Intentions in Traditional Society}

The characteristics of the traditional social fertility intention is advocating children much happiness. It has a strong boy preference. It attaches great importance to the quantity, quality of contempt. This is closely related to the traditional agriculture society. Early due to China's economic and social development level is not high, most of the residents in our country birth will show the willingness of a traditional society to breed. This early from our social imbalance of sex ratio can see obviously. Fifth national population census, in 2000 the national birth population sex ratio is 106.74 , the ratio is 106.74 in babies born: 100.Sixth census in 2010 showed the sex ratio in China is generally 105.20:100.Men than women in general newborn baby.

The implementation of the two-child policy will reduce the dependency ratio of society, scholars, according to the original new prediction to implement separate two-child policy compared with the current policy unchanged, the working age population will increase, the new labor force will lower the elderly dependency ratio.

\section{B. The Birth Desire in Mordern Society}

The birth of modern society will tend to have fewer, no gender preference, attaches great importance to the quality of their children. Due to the great development of social productive forces, the value orientation of people big changes, generally attach importance to individual development, personal dilemma gradually become the mainstream. With the continuous development of social economy, the number of children will limit the individual development; as a result, the fertility intentions will become the mainstream of modern society's fertility intentions.

So most of them were approved second child support for the domestic economy and pension security role for parents, people at the same time with two optimization children education quality, and improve the spiritual satisfaction, family members are more recognition, enhance the effect of family happiness, the main reason is probably now one-child problem is more serious, for spoiled children, and children is not sensible, often lead to family conflicts, even burst [12]. For an only child at the same time, they don't have a brother and sister, growing up lonely, are often not very good with people, serious 
self thought, character has certain defects. If two births, will reduce to spoil a child, the child will help each other between, promote each other, with growth, the family will be more harmonious. This is good for the development of the society as a whole.

\section{The Expected Results of the Two-child Policy}

Fertility concept this paper involves mainly refers to people in sociology and actual birth level, it is the main indicator of measuring fertility. But because the birth rate due to factors such as gender, age and other demographics, cannot fully reflect the fertility of the population. And reproductive output compared with the number of women of childbearing age, can very good reaction average fertility of the population. Throughout several census data, due to the implementation of the one-child policy, from the initial high fertility in China has gradually reduce, the end of last century our country into the low birth level, this kind of low birth level will also continue, but the academic circles also expressed concern that hinder the sustainable development of population, and population will produce a series of problems [10]. Only maintaining moderate fertility can guarantee the sustainable development of population.

All the provinces and autonomous regions in China began to gradually fall launch separate two-child policy, the policy will be born a modest increase in the number, the new baby's consumption is to expand the current urgently needs to increase the domestic demand of the market, and in these children start to work, just can greatly reduce the labor resources shrinking fast and rapid increase of the population proportion of elderly people debt pressure, promote economic and social sustainable development [9].

\section{SUMMARY}

Attaches great importance to the family for children in China result in raising cost and education costs soaring, and pressure from economic nature will lead to the increase of career development pressure and the time and effort, it is also a lot of families is not willing to the main reason for the two births. And education child pressure is strong correlation with the time and effort, reveals the family concerns common to her children's education problem stems from a little time for their children, their energy CO., LTD. In terms of utility, economic support and old-age security and education optimization is strong correlation, that now because pension costs and the rising cost of education to economic support, good family economic conditions will naturally good old-age security and child education condition, at the same time old-age security and inheritance responsibility and spirit to meet strong correlation. Visible hope birth children to have consideration to the old-age security, the improvement of old-age security will increase two births spiritual satisfaction.

\section{REFERENCES}

[1] Junsen Zhang. Do population control policies induce more human capital investment? Twins, birth weight and Chinese One-Child policy. The review of economic studies. 2008

[2] Takeushi S. Yumoto.Consider the Earth. 1997

[3] Li Hongbin, Zhang Junsen, Zhu Yi. The effect of the One-Child Policy on Fertility in China: Identification Based on the Differences-inDifferences. Journal of Women s Health. 2005

[4] Terence H, Wen Xingyan. Rising sex ratios at birth in China: evidence from the 1990 population census. the international seminar on Chinese 1990 population census. 1992

[5] Longbin Li, Lena Edlund, Junjian Yi, Junsen Zhang. Sex ratios and crime: evidence from China. 2007

[6] United Nations. World Population Prospects, The 1998 Revision. 1999

[7] United Nations. World Popnlation Prospect: The 2004 Revisions. 2005

[8] Anup Shah. Ecology and the Crisis of Overpopulation Future Prospects for Global Sustainability. 1998

[9] John Bongaarts, Susan Greenhalgh. An Alternative to the One-child Policy in China. Population and Development Review. 1985

[10] John Bongaarts, Susan Greenhalgh. An Alternative to the One-child Policy in China. Population and Develpment Review. 1985

[11] Anup Shah. Ecology and the Crisis of Overpopulation-Future Prospects for Global Sustainability. 1998

[12] United Nations.1990 Demographic Yearbook. 1992 